\title{
Homenaje A Lester EMBree
}

\section{HomAge to Lester EMBREe}

Francesc Perenya / Pau Pedragosa Universitat de Barcelona / Universitat Politècnica de Catalunya perena@ub.edu / papebo@yahoo.com

Nuestra contribución al merecido homenaje al amigo Lester Embree consistirá en explicar nuestra experiencia personal y la de nuestro grupo, el Grup d'Estudis Fenomenològics de la Societat Catalana de filosofía, con Lester. Hay que decir, ante todo, que las palabras que siguen representan la contribución del grupo mismo al reconocimiento y agradecimiento al maestro. Reconocimiento y agradecimiento debidos a alguien que, aparte de sus relevantes aportaciones individuales, tanto ha hecho por la convivencia, por el "co-filosofar" (por usar una expresión de Husserl) de los fenomenólogos de todas partes del mundo. Ciertamente, "el movimiento fenomenológico" no representa la "Phänomenologengemeinschaft" que Husserl había aspirado a fundar como una comunidad científica. Más bien encarna la pluralidad de direcciones, orientaciones y disensiones a que dio lugar la fenomenología husserliana, unidas por lo que podríamos llamar "espíritu fenomenológico" en sentido amplio. La investigación fenomenológica actual responde a su vez a esta pluralidad. Pero la "Organización de Organizaciones Fenomenológicas" (O.P.O.) reúne a los diversos grupos en este espíritu $y$, aun sin ser tampoco una comunidad científica, tiene el carácter de una comunidad, la forma de la "intersubjetividad" y de la comunicación. Y si la intersubjetividad tiene su fundamento en la empatía, esta preside los encuentros de la O.P.O. en los diversos rincones y continentes del mundo El maestro Embree es un maestro de la empatía, y esta circunstancia no es en modo alguno ajena a 
la existencia de la Organización. Una empatía que nuestro pequeño grupo ha tenido el privilegio de experimentar y que ha contribuido a darle vida.

A continuación presentamos las experiencias personales y algunos comentarios y glosas de la figura de Lester Embree por parte de Francesc Perenya y Pau Pedragosa en nombre del Grup d’Estudis Fenomenològics de la Societat Catalana de Filosofía (G.E.F.).

\section{POR FRANCESC PERENYA:}

La relación con Lester empezó con una carta que recibí en verano de 2002, un día antes de marcharme de Barcelona de vacaciones. No sé exactamente cómo, se había enterado de la existencia de nuestro pequeño grupo fenomenológico y me invitaba a participar en la fundación de la O.P.O. en Praga en el mes de noviembre. Tuve que improvisar una respuesta explicándole quiénes éramos y acepté la invitación. Preparé una pequeña ponencia para el congreso fundacional, y al llegar a Praga le conocí personalmente.

Recuerdo que su imponente humanidad (aunque sólo me superaba en la dimensión vertical) y su simpatía y carácter acogedor me causaron una gran impresión. En aquel congreso, en el que participaron representantes de muchos más grupos de estudiosos de la fenomenología de los que yo podía creer que existían, desde grupos pequeños como el nuestro hasta las grandes instituciones como el Husserl-Archiv, se fundó una institución que ha sido decisiva para la difusión de la fenomenología por todos los rincones del mundo.

Desde entonces la relación de nuestro grupo con Lester ha sido constante (ya lo era desde antes con la SEFE, la Sociedad Española de Fenomenología). Creo que la generosidad es una de sus principales virtudes, que en nuestro caso se concretó en una visita en la que él mismo corrió con todos los gastos. Para compensarlo un poco, para salvar la cara, por así decir, Xavier Escribano tuvo a bien organizar y financiar una conferencia en la Escuela de Enfermería de la UIC, en el Hospital General de Catalunya. La conferencia se titulaba: "My visit to phenomenological Nursing" y tuvo lugar el 13 de diciembre de $2012^{1}$. En la conferencia para nuestro grupo estábamos los cuatro gatos fenomenólogos de siempre; en cambio, la conferencia en el hospital tuvo una asistencia masiva. Allí

${ }^{1}$ Es esta conferencia, traducida por Xavier Escribano, la que aparece publicada al inicio de este voumen. 
Lester ofreció un ejemplo de su decisiva contribución a la aplicación del método fenomenológico a todos los fenómenos humanos y culturales. Por otra parte: el clima que se creó y el debate que surgió, evidenciaron la enorme receptividad de los profesionales de la enfermería para el mensaje recibido. Fue un acto comunicativo plenamente logrado. Y no hay duda que la voluntad y capacidad de comunicación de Lester es una de las claves de su aportación a la difusión de la fenomenología.

Otro ejemplo de generosidad con nuestro grupo y de voluntad de llevar la fenomenología a todas partes ( $y$ a todas las lenguas) fue el hecho de que facilitó y, al menos en parte, financió la traducción al catalán des su "Análisis reflexivo", que corrió a cargo de Carles Serra.

POR PAU PEDREgosa:

En este breve homenaje y recuerdo a mi amigo Lester Embree me gustaría empezar con lo que me parece ser su aportación más relevante a la fenomenología pues creo que esta aportación ayuda a comprender su carácter afable, tolerante y abierto gracias al cual pudimos trabar una hermosa amistad.

Si algo define la aportación de Lester a los estudios fenomenológicos es lo que tal vez de manera inadecuada se llama aplicación del método fenomenológico. En sus numerosas intervenciones públicas, Lester acostumbraba a decir algo así como que los fenomenólogos se han limitado a interpretar el método, pero lo que importa es aplicarlo. Ciertamente, el método debe seguir siendo interpretado pues neutralizar la actitud natural sigue teniendo, ahora como siempre, en tanto que parte esencial de la tarea original de la filosofía, una gran dificultad; pero Lester sostenía que el cuestionamiento constante del método no puede hacerse al margen de su misma aplicación a fenómenos particulares. No hay una interrogación del método al margen de su uso pues, parecía sostener Lester, el método se pone a prueba en su eficacia descriptiva, y ulteriormente explicativa, de los distintos campos del conocimiento a los que el método se aplique. La obra de Lester recupera de este modo el impulso original de la primera generación de discípulos de Husserl que aportaron estudios rigurosos en distintos campos como el derecho (Adolf Reinach), el arte (Roman Ingarden, Moritz Geiger), la empatía (Edith Stein), el mundo social (Alfred Schutz). 
De este cuestionamiento y crítica a aquellos que se quedan encerrados en la disciplina fenomenológica y su problemática interna se desprende otro aspecto de su obra, la interdisciplinariedad, que es de una enorme actualidad y relevancia a principios del siglo XXI, un siglo más preocupado por el cruce de conocimientos que por la pureza y autonomía de las disciplinas, una característica de nuestro tiempo, por cierto, muy diferente de aquella que dio nacimiento a la fenomenología. Es un gran mérito de la obra de Lester haber revitalizado la fenomenología en nuestra época haciéndole un espacio propio en el complejo y plural panorama de los saberes contemporáneos en la medida que se puede relacionar con todos ellos aportando un método.

Su insistencia e incansable difusión internacional de la importancia de hacer rendir la fenomenología en otros campos del saber y de la práctica, de hacer fenomenología "de", atrajo mi atención cuando estaba trabajando en la elaboración de una fenomenología de la arquitectura. Cuando le conocí y le expliqué mi proyecto respondió con alegría y entusiasmo sinceros; la alegría y el entusiasmo de quien conoce a alguien que, como él, está trabajando en la misma dirección; la alegría que surge de reconocer que su proyecto más querido, el de llevar la fenomenología más allá de las fronteras de la filosofía y fomentar la interdisciplinariedad, se está realizando en distintos países, en distintas lenguas, por parte de investigadores repartidos por todo el mundo; una alegría y un entusiasmo, en definitiva, que nunca dejó de transmitirme en años sucesivos y que además fomentó, dispuesto como estaba siempre a ayudar para que la gente se conociera y colaborara. En este espíritu colaborativo me recomendó y facilitó datos de contacto de fenomenólogos de otros países, desde China a Estados Unidos, que podrían ayudarme en mi tarea.

Mi experiencia personal y amistad con Lester junto a su aportación al movimiento fenomenológico me permite dibujar el perfil de Lester, su personalidad, como alguien sumamente interesado en poner en contacto a distintos fenomenólogos para que se conocieran y trabajaran juntos, pero no solo fenomenólogos, sino investigadores de todos los ámbitos. Una persona, pues, cordial, abierta al otro, afable, siempre dispuesta a ayudar y a abrir la filosofía a todo el mundo mediante el uso de un lenguaje alejado de los tecnicismos de la disciplina sin caer por ello en la simplificación. Alérgico a los purismos y dogmatismos a los que podría llevar un empecinamiento en habitar exclusivamente dentro una es- 
fera del saber, expresaba una apertura y curiosidad en el mejor sentido cosmopolita. Gran viajante y amante de todas las culturas, lenguas y costumbres, podríamos decir que Lester Embree encarnaba su idea de la fenomenología.

iGracias, Lester, por tu amistad y tus enseñanzas! 